\title{
Valuing the digital economy
}

\section{Wired for Innovation: How Information Technology is Reshaping the Economy Erik Brynjolfsson and Adam Saunders MIT Press: 2009. 134 pp. \$18.95, £14.95}

Information technology has clearly had an impact on our daily lives. It has also altered the global economy. But how can you measure the worth of a web search or an electronic file format? In this slender volume, Erik Brynjolfsson and Adam Saunders examine the links between innovation, productivity and value.

Wired for Innovation contrasts information with tangible goods. Unlike a physical product, information is not limited by its transportability or the number of times it can be used. Yet a consumer who uses a web search to book a holiday, for example, adds real value to the economy and more than 8 billion web searches are made each day in the United States alone. Forming a demonstrable relationship between web activities and dollars generated is becoming increasingly important.

To illustrate why traditional economic measures are inadequate, Brynjolfsson and Saunders examine the impact of web-based products that seem, to the consumer, to be free, such as Google's search engine or Adobe's portable document format. These, they explain, follow two-sided markets: many search engines receive funding from keyword-based advertising, and Adobe makes money from selling other software products that use its file format. But the connections between the two sides of the business are invisible. Because Adobe doesn't sell its Reader, the contribution of that software to a traditional metric such as gross domestic product cannot be determined.

However, networked technologies also offer new ways to manage and analyse economic data at an increasingly fine-grained scale. The authors propose a tool kit for the emerging economics of the digital business world. Different devices are needed to monitor and test the market as it evolves. Some of their suggested indicators are not new, such as customer surplus - the aggregate net benefit that consumers receive from an item or service above what they paid for it - but they take on a new role in the digital environment.

The combination of mobile phones, global positioning systems, online maps and restaurant reviews, for example, has opened up

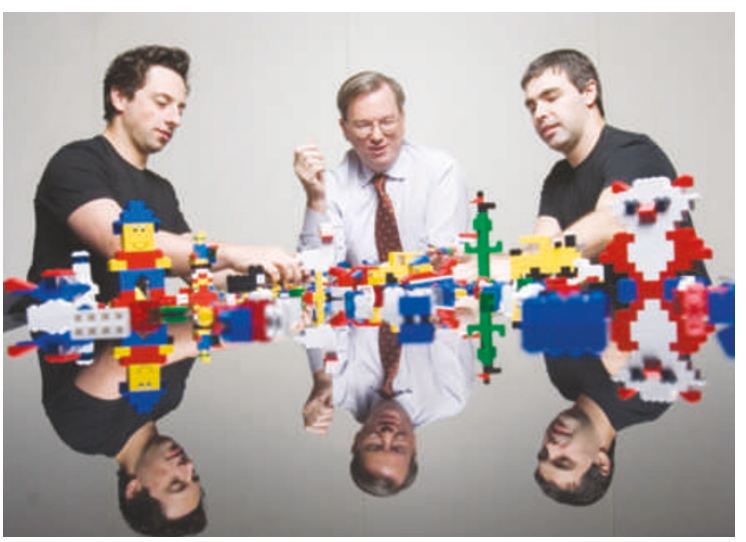

Web-based wonders: Google founders Sergey Brin (left) and Larry Page (right) and chief executive Eric Schmidt. possibilities for revenues whose value exceeds that for each technology alone. Measuring that surplus requires further technologies to track links in the economic decision chain, such as smart 'sociometric' badges that monitor interpersonal interactions. Such developments would allow us to monitor flows of information through the economic and social system at a detailed level.

The human side of innovation must also be understood. Brynjolfsson and Saunders explain that information systems are meaningless without the ability to manage and accrue benefits from them. They propose "pillars" that should underpin a successful digital organization - where people are supported by technology, rather than the other way around. Open information access, rather than an excessively protective communication policy, is cited as one way for an organization to draw benefit from the human skills available to it - what you can't see, you can't extract value from.

Future economists and computer scientists may look to this decade as the beginning of a digital global economy. Small, light and portable, like the technologies it describes, Wired for Innovation will form a valuable reference for scholars searching for markers of this fundamental change. Those wishing to become a formative part of the new economy - rather than merely a footnote - should read this book.

John Gilbey lectures in computer science at Aberystwyth University, UK. e-mail: gilbey@bcs.org.uk

\section{Tips from the top of the career ladder}

\section{Beyond the Boys' Club: Strategies for Achieving Career Success as a Woman Working in a Male-dominated Field Suzanne Doyle-Morris \\ Wit and Wisdom Press: 2009 \\ 298 pp. $€ 13.99, \$ 22.99$}

As an executive coach who works with companies to recruit, retain and develop their female talent, Suzanne Doyle-Morris has long had an interest in issues concerning women in maledominated professions, including academia and science. In her book, she offers advice to anyone who wishes to "understand the boys' club and move beyond it".

Doyle-Morris interviewed 21 senior women from a range of backgrounds to discover what made them survive and thrive in their workplaces. Her interviewees, spanning a wide age group, included a senior diplomat, a retired archaeologist who led digs in Iraq, and academics such as Athene Donald, professor of experimental physics at the University of Cambridge and 2009 recipient of a L'Oréal/ UNESCO Women in Science award.

The difficulties women face in rising through their professions, Doyle-Morris argues, stem largely from old career structures. Too often it is assumed that an employee, usually male, has a partner, usually female, who will attend to domestic responsibilities, leaving the employee free to focus on work. As more women enter the workforce, they realize that this model does not suit them and they are made to feel inadequate if they do not play by the rules of this game.

Moreover, career advancement is not based entirely on merit. "People who get ahead are those who make others aware of their wins, and those who spend time developing relationships and their own personal profile," Doyle-Morris explains. As $80 \%$ of consumer decisions are said to be made by women, it makes good business sense for companies to put more women in senior positions. But even so, the rise to the top can be slow, especially in the science and engineering professions. In the United Kingdom, DoyleMorris says, about $70 \%$ of women holding degrees in science, engineering or technology 
do not currently work in these fields.

In addition to focusing on how individual women can develop strategies for success, Beyond the Boys' Club highlights effective government legislation. In Norway in 2002, for example, the government proposed legislation requiring $40 \%$ female representation on companies' executive boards, and by the dead-

line of 2008 the target had been reached.

Quotas and affirmative-action policies are often frowned upon by sceptics, who argue that this will lead to a loss of quality. But DoyleMorris points out that men have always benefited from favours within male networks. "Most

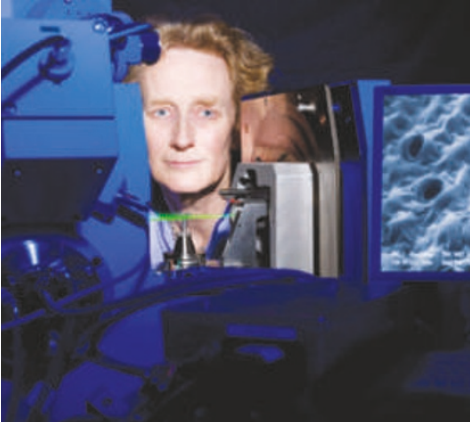

men know that building relationships for mutual benefit is the only way to build a career," she notes, so women should not be afraid to do the same.

The book explains how best to develop these relationships. It offers tips on how to raise your profile, build your image, network within and outside the organization, take appropriate risks, negotiate office politics and choose a mentor or coach.

Although Doyle-Morris addresses most of these strategies to women working in companies, two professors add advice from academia. They discuss mentoring in universities and the use of flexible working time in their laboratories. They suggest specializing in a field other than your PhD topic during the postdoc years, and finding cross-disciplinary collaborations. However, they don't address more particular problems, such as how to complete your doctorate if you suffer sexual harassment from a supervisor, or how to maximize visibility for your work in order to gain an influential position such as dean or president of a university.

Doyle-Morris has great experience and a passion for her subject. I hope she will write a sequel offering strategies for women in academic science - and that the sequel will offer insights from women belonging to different class backgrounds, races, nationalities, sexual orientations and physical abilities.

Asha Gopinathan is a researcher in neuroscience based in Trivandrum, India.

e-mail: dendron.15@gmail.com

\section{Q\&A: The algorist}

Having moved from engineering to art, Jean-Pierre Hébert applies mathematical rules to generate artworks that explore themes of chaos and determinism. As resident artist at the Kavli Institute for Theoretical Physics, and with an exhibition on in Los Angeles, Hébert explains his interest in algorithms.

\section{How did you become fascinated by algorithms?}

At 19, I was exposed to the first computer that came to Europe. I took a summer job at IBM and became interested in mathematics and computer science. My taste in art was influenced by Mondrian and the Bauhaus. I was very interested in geometry. Soon I made algorithmic pieces by hand. Then I figured that I could program that.

Some of your works are computer-drawn, others are sculptures. Which do you prefer?

I have more affinity with the physical than the virtual world. I like to mark paper or water or sand, and I like to explore algorithms without using computers. There is a richness in something beautifully made on paper, stone, clay or canvas that is more inspiring than a flat image.

\section{How have you interacted with researchers?}

I've always had a strong interest in physics. In collaborations with scientists I learnt about new phenomena in physics and nature and about new ways to express them. I have learnt tricks to define spirals and made graphical presentations of the gravitation around black holes.

\section{How did your style develop?}

At first my work was monochromatic and flat, and used only certain themes in geometry. I wanted to animate it more and make it happen in three dimensions to make it subject to fields and forces and waves, and to submit it to phenomena like reflections on the surface of water.

\section{How did you define the 'algorist' movement?}

We established, 40 years ago, that the work should



be based on algorithms but it should also produce an object of art - something concrete, such as a drawing, a painting, a sculpture, a piece of music. It should not be simply the concept behind an algorithm.

\section{Are algorithms important in art?}

Over the past century most artists were algorists, even if they did not know it. Mondrian has an algorithm; cubism was a set of algorithms. Algorithms are just a tool, as is a computer, a brush or a pencil. The personality of the artist takes over and should transpire through the work. Algorithms are not an end in themselves.

Interview by Nature reporter Daniel Cressey.

Jean-Pierre Hébert: Drawings as Thoughts $\mathrm{SCl}$-Arc Library, Southern California Institute of Architecture, Los Angeles until 13 December 2009

Kavli Institute for Theoretical Physics, University of California, Santa Barbara A sand sculpture has been placed on permanent display. 